\title{
Challenging a Myth: Directional Atherectomy
}

\author{
Jim Reekers
}

Received: 4 August 2008/Accepted: 3 September 2008/Published online: 30 January 2009

(c) The Author(s) 2009. This article is published with open access at Springerlink.com

Percutaneous atherectomy was first introduced as an alternative to balloon angioplasty (BA) in 1986 to improve the results that could be achieved with BA [1]. The advantages of atherectomy were the creation of a smooth luminal surface with less local thrombosis and the reduction of elastic recoil because the lumen can widen without stretching the arterial wall. In percutaneous atherectomy the atheromatous intima usually occurs with or without the media. The notion that the "bad" atheroma would be removed is also an appealing feature of this technique.

Atherectomy can be divided into extirpative atherectomy, which means cutting and/or shaving and removing the atherosclerotic material from the patient, and ablative atherectomy, where the atheroma is fragmented with a high-speed device. The Simpson atherectomy catheter is an example of extirpative atherectomy, and the Kensey catheter and the rotablator are examples of ablative devices. The term "directional" means that the catheter removes one sector or direction of the vessel-wall atheroma.

Eleven studies of the Simpson atherectomy device were published between 1988 and 1993. Excluding 2 studies that did not publish technical success, a total of 908 patients were reported. The technical success rate was reported at approximately $90 \%$, and complications, mainly peripheral embolisation, were reported to be between $3 \%$ and $21 \%$ (median 4\%).

Six-month follow-up was available in eight reports, and patency by different definitions varied between $80 \%$ and $99 \%$. Twelve-month follow-up of $71 \%$ to $94 \%$ was reported in only five reports. Only one article reported 24-

J. Reekers $(\bowtie)$

Department of Radiology, Academic Medical Center,

Amsterdam, The Netherlands

e-mail: j.a.reekers@amc.uva.nl month follow-up of a lager group of patients. The 24months patency has since decreased to $37 \%$ [2].

The previous papers is typical for older interventional radiology (IR) publications concentrating on the technique but with less focus on long-term outcome or real evidence for effectiveness. In 1995, Vroegindeweij et al. [3] published data from a prospective randomized trial comparing BA with atherectomy. This is an example of probably the earliest randomized controlled trial (RCT) concerning peripheral interventional techniques. Although the total series is small ( $n=73$ patients), the outcome is clear and significant. Atherectomy does not result in improved clinical and hemodynamic outcome. Furthermore, atherectomy of segmental atherosclerotic femoropopliteal disease does not result in a better patency rate than $\mathrm{BA}$; in patients with lesions longer than $2 \mathrm{~cm}$, atherectomy results are significantly worse.

So, the myth was busted and that was the end of directional atherectomy, one could say. However, it is well known that IR is a profession of the future, so we should never look back. Yes, directional atherectomy publications died out during the next 2 decades; then in approximately 2005, a well-orchestrated new directional atherectomy offensive began. The system was presented as "new" and promising. There was an early registry and enthusiastic presentations at many angioclubs, and IR meetings were held by small groups of physicians [4]. Again, directional atherectomy was booming once again. This time not only medical journals were involved, there was also a publication in the Wall Street Journal in August 2005: Physicians Testing SilverHawk Catheter Also Own Stock Options was the title of the warning article. Twelve doctors supplied information about the catheter's effectiveness to a registry that the company used to evaluate the SilverHawk (EV3, USA) - its only product-and to promote it to other 
doctors. The article concluded with the warning that the results were anecdotal.

By now (2008), new reports have shown that directional atherectomy, also performed with the "new" device, has no additional value to BA but moreover carries a high risk for peripheral embolization, which was not noted in the original registry [5-7]. Is the myth now finally busted? Some myths must be busted twice. However, in IR you never know.

Open Access This article is distributed under the terms of the Creative Commons Attribution Noncommercial License which permits any noncommercial use, distribution, and reproduction in any medium, provided the original author(s) and source are credited.

\section{References}

1. Simpson JB, Zimmerman JJ, Selmon RM et al (1986) Transluminal atherectomy: initial clinical results in 27 patients. Circulation 74(Suppl II):203
2. Katzen BT, Becker GJ, Benenatti JF et al (1992) Long-term follow-up of directional atherectomy in femoral and popliteal arteries. J Vasc Interv Radiol 3:38-39

3. Vroegindeweij D, Tielbeek AV, Buth J et al (1995) Directional atherectomy versus balloon angioplasty in segmental femoropopliteal artery disease: two years follow-up using color flow duplex. J Vasc Surg 21:235-269

4. Ramaiah V, Gammon R, Kieszs S et al (2006) Midterm outcomes from the TALON Registry: treating peripherals with SilverHawk: outcomes collection. J Endovasc Ther 13:592-602

5. Keeling WB, Shames ML, Stone PA et al (2007) Plaque excision with the SilverHawk catheter: early results in patients with claudication or critical limb ischemia. J Vasc Surg 45:25-31

6. Lam RC, Shah S, Faries PL, McKinsey JF, Kent KC, Morrissey HJ (2007) Incidence and clinical significance of digital embolization during percutaneous interventions involving the superficial femoral artery. J Vasc Surg 46:1155-1159

7. Chung SW, Sharafuddun MJ, Chigurupat R, Hoballah JJ (2008) Midterm patency following atherectomy for infrainguinal occlusive disease: a word of caution. Ann Vasc Surg 22:358-365 